\title{
Post-treatment Surveillance for Stage I and II Non-small Cell Lung Cancer: Impact on Clinical Outcome
}

\author{
RENATA KARZIJN ${ }^{1 *}$, LEONIE ALBERTS $^{1 *}$, JOHANNES C. KELDER ${ }^{2}$, FREDERIK N. HOFMAN $^{3}$, \\ SHERIF Y. EL. SHAROUNI ${ }^{4}$, ELISABETH A. KASTELIJN ${ }^{1}$ and FRANZ M.N.H. SCHRAMEL ${ }^{1}$ \\ Departments of ${ }^{1}$ Pulmonology, ${ }^{2}$ Epidemiology and Statistics and \\ ${ }^{3}$ Cardiothoracic Surgery, St. Antonius Hospital, Nieuwegein, the Netherlands; \\ ${ }^{4}$ Department of Radiotherapy, University Medical Centre Utrecht, Utrecht, the Netherlands
}

\begin{abstract}
Background/Aim: Patients treated for earlystage non-small cell lung cancer (NSCLC) need posttreatment surveillance for detecting recurrence of disease. The aim of this study was to provide evidence for the appropriate follow-up. Patients and Methods: The overall survival (OS), 1- and 3-year survival and progression-free survival (PFS) were retrospectively compared between two imaging modality groups. One group received only chest radiographs (CR group) and one group received chest radiographs and at least one computed tomography scan (CT group). Results: Patients in the CR group ( $n=50)$ had no inferior $O S$ (hazard ratio $(H R)=1.427,95 \%$ confidence interval $(C I)=0.755-2.695, p=0.273)$ and PFS $(H R=1.156$, 95\% CI=0.645-2.069, $p=0.627)$ compared to patients in the CT group (n=23). Both 1 - and 3-year survival were equal in the two groups $(H R=5.544,95 \% C I=0.530-58.031$, $p=0.153$ and $H R=1.540,95 \% C I=0.752-3.154, p=0.238$, respectively). Conclusion: Follow-up with a chest radiography did not result in inferior clinical outcomes compared to follow-up with a CT scan.
\end{abstract}

Lung cancer is the leading cause of cancer-related deaths worldwide (1). Non-small cell lung cancer (NSCLC) is the most common (approximately 85-90\%) established form of lung cancer and $30 \%$ of patients present in an early stage of disease (defined as stage I and II) (2).

*These Authors contributed equally to this work.

Correspondence to: Franz M.N.H. Schramel, Department of Pulmonology, St. Antonius Hospital, PO Box 2500, 3430 EM Nieuwegein, The Netherlands. Tel: +31 883201425, Fax: +31 883201449, e-mail: f.schramel@antoniusziekenhuis.nl

Key Words: Early-stage non-small cell lung cancer, overall survival, progression free survival, surveillance, chest radiography, CT scan.
The standard treatment for stage I and II NSCLC is surgical resection of the tumor. However, stereotactic body radiotherapy (SBRT) is a good alternative treatment with equal outcomes in terms of survival and recurrence rates (3-5). Patients who completed curative-intended therapy are at higher risk for developing a second primary lung cancer (metachronous tumor) or recurrent disease compared to the general population (6). Therefore, surveillance after treatment is of importance to provide care without delay, since an early intervention could increase survival and might improve quality of life (7-9).

A myriad of international recommendations concerning the intervals and types of imaging modalities (chest radiography and computed tomography (CT) scan) for post-treatment surveillance regimes exist for stage I and II NSCLC. Advantages of a chest radiography are that it is less expensive and easy to perform technique compared and to compared to a CT scan. A disadvantage is the risk that tumors of $2 \mathrm{~cm}$ or smaller may not be detected, whereas a CT scan detects more nodules and lung cancers in an early phase. However, a CT scan provides more radiation exposure and may lead to more false-positives that can result in invasive diagnostic procedures that are costly and can cause morbidity $(10,11)$. Many guidelines have been developed, all based on observational studies and systemic reviews, since no randomized controlled trials have been performed. The European Society of Medical Oncology (ESMO) and National Comprehensive Cancer Network (NCCN) recommend a chest CT scan every six months, the anti-cancer American College of Chest Physicians (ACCP) recommends a chest radiography or CT scan every six months the first two years post-treatment (12-14). Studies that investigate outcomes after either follow-up with a chest radiography or with a CT scan are scarce.

To further establish the appropriate follow-up modality, the aim of this study was to investigate the clinical outcomes of patients with recurrence of earlier curative treated stage I and II NSCLC who underwent surveillance with a chest radiography or with a CT scan. 


\section{Patients and Methods}

The current study retrospectively reviewed the medical records of all patients diagnosed with a recurrence of previous treated stage I and II NSCLC in the Sint Antonius Hospital, Nieuwegein, the Netherlands, between 2008 and 2014. Treatment consisted of either SBRT or surgical resection of the tumour. Exclusion criteria were lack of follow-up, treatment with induction chemotherapy or more than one tumor at the time of diagnosis.

The diagnostic work-up and treatment with SBRT or surgical resection of this cohort have been described earlier (4).

The follow-up schedule consisted of a clinical visit every three months during the first two years and every three to six months the years thereafter. During the visits, a thorough medical history and physical examination were carried out and, in addition, a chest radiography or a CT scan to detect recurrence of disease was made. A CT scan was also performed in case of changes on the chest radiography and/or suspected clinical symptoms. Fludeoxyglucosepositron emission tomography (( $\left.{ }^{18} \mathrm{~F}-\right)$ FDG-PET) scans were obtained for further evaluation of concerning findings on other imaging modalities.

Surveillance after therapy started on the first day of treatment. Progression of disease was defined as locoregional recurrence (LRR) or distant recurrence (DR). Locoregional recurrences was defined as recurrence in or adjacent to the planning target volume or surgical resection or in the ipsilateral hilum or mediastinum. Recurrences that could not be defined as LRR were considered as DR. Recurrence in surgical patients was confirmed either by biopsy or by ${ }^{18}$ F-FDG-PET scan. Recurrence in SBRT patients was determined by biopsy, by ${ }^{18} \mathrm{~F}-\mathrm{FDG}-\mathrm{PET}$ scan or determined as clinically based on imaging. The day of recurrence was defined as the first observation of the new detected lesion. In this study, patients with recurrence of disease within three months of treatment were excluded because they could not have their first regular follow-up.

The overall survival (OS) is defined as the time between the first date of treatment and the date of death from any cause or the end of follow-up with or without disease. The median follow-up was defined as the time from the start of treatment until death or end of follow-up. Progression-free survival (PFS) was defined as the time from the start of treatment until tumor recurrence. Patients alive at the end of this study (i.e. December 2014) were censored. In this study, patients were categorized in two groups based on the surveillance after treatment: a group receiving CT scans with or without chest radiographs (CT group) and a group receiving followup by chest radiographs without CT scans (CR group).

Statistical analysis. The primary end point was OS after post therapy surveillance with a chest radiography compared to followup with a CT scan. The secondary end point was PFS compared in both imaging modality groups.

Continuous data were presented as the mean \pm standard deviation. The differences between the two imaging modality groups were tested with the Student's $t$-test. Categorical data were expressed as frequencies and percentages. The Pearson's Chi square test and Fisher's exact test were used to test differences between the two arms. Survival rates in both imaging modality groups were evaluated and compared by Kaplan-Meier survival and with the logrank test and the Cox proportional hazard analysis. To correct for potential bias in the selection of $\mathrm{CR}$ group versus CT group, we determined our candidate factors. Candidate factors were described as factors with $p \leq 0.100$ on baseline and/or on univariate analysis and were incorporated into a multivariable model for primary and secondary end points. The diffusing capacity of the lung for carbon monoxide (DLCO) values were not available for two patients from the CR group and one patient from the CT group. All statistical analyses were two-sided and values of $p<0.05$ were considered statistically significant. Statistical analyses were performed with the SPSS statistical software program package version 23.0 (SPSS Inc., Chicago, IL, USA).

\section{Results}

Stage I and II NSCLC was diagnosed in 228 patients between 2008 and 2011. A total of 86 patients developed recurrence of disease. Thirteen patients were excluded, nine patients due to loss to follow-up visits and four patients because of recurrence of disease within three months post-treatment.

Patients' characteristics. The baseline characteristics are presented in Table I. Of the 73 patients, 22 patients were treated with SBRT and 51 patients underwent surgical resection. Most patients received only chest radiographs during follow-up (50 patients, 68\%), whereas 15 patients received one $\mathrm{CT}$, six patients $2 \mathrm{CT}$ scans, one patient $4 \mathrm{CT}$ scans and one patient $5 \mathrm{CT}$ scans. Patients treated with surgical resection, received more often a chest radiography compared to patients who had undergone SBRT $(78 \%$ compared to $46 \%$ in the CT group, $p=0.005)$. Furthermore, in the CT group, both forced expiratory volume in 1 second (FEV1) and DLCO were lower.

Overall survival. On baseline and/or univariate analysis, the ECOG performance status, FEV1, DLCO, morphology and primary treatment were considered as candidate factors for both primary and secondary outcomes (Table II). On multivariate analysis, ECOG turned out to have a statistically significant relationship with survival; patients with an ECOG 0 (hazard ratio $(\mathrm{HR})=0.060,95 \%$ confidence interval $(\mathrm{CI})=0.008-0.453, p=0.006)$ and ECOG $1(\mathrm{HR}=0.091,95 \%$ $\mathrm{CI}=0.014-0.584, p=0.011)$ are at lower risk of dying than patients with ECOG 2 (reference). Squamous cell carcinoma had a favorable position for surviving compared to 'other morphology' (HR=0.345, 95\% CI=0.124-0.957, $p=0.041)$. It turned out that there were no confounders in this study.

The median OS was 22.1 months (interquartile range $(\mathrm{IQR})=14.2-39.2)$ in the $\mathrm{CR}$ group versus 27.2 months $(\mathrm{IQR}=18.5-53.2)$ in the $\mathrm{CT}$ group $(p=0.122)$. After adjustment for the ECOG performance score and morphology, OS was not different in both groups $(\mathrm{HR}=1.427,95 \% \mathrm{CI}=0.755-2.695, p=0.273)$ (Figure 1). Furthermore, the number of CT scans (independent from contemporary chest radiographs) made during follow-up did not influence OS $(p=0.606)$. 
Table I. Baseline patients' characteristics.

\begin{tabular}{|c|c|c|c|c|}
\hline & $\begin{array}{l}\text { Total } \\
\mathrm{n}=73\end{array}$ & $\begin{array}{c}\text { CR group } \\
\mathrm{n}=50\end{array}$ & $\begin{array}{l}\text { CT group } \\
\mathrm{n}=23\end{array}$ & $\begin{array}{l}p \text {-Value } \\
\text { n.a. }\end{array}$ \\
\hline \multicolumn{5}{|l|}{ Gender (no.) } \\
\hline Male & 40 & 29 & 11 & \multirow[t]{2}{*}{0.417} \\
\hline Female & 33 & 21 & 12 & \\
\hline Age (years) & $66,4( \pm 10.5)$ & $66,5( \pm 8.9)$ & $66,0( \pm 13.5)$ & 0.853 \\
\hline \multicolumn{5}{|l|}{ Smoking history } \\
\hline$<30 \mathrm{PY}$ & 35 & 22 & 13 & \multirow[t]{4}{*}{0.548} \\
\hline 30-39 PY & 12 & 10 & 2 & \\
\hline$>40 \mathrm{PY}$ & 24 & 17 & 7 & \\
\hline Unknown & 2 & 1 & 1 & \\
\hline \multicolumn{5}{|l|}{ Primary c-TNM } \\
\hline Ia & 37 & 22 & 15 & \multirow[t]{4}{*}{0.300} \\
\hline $\mathrm{Ib}$ & 17 & 12 & 5 & \\
\hline IIa & 14 & 12 & 2 & \\
\hline $\mathrm{IIb}$ & 5 & 4 & 1 & \\
\hline \multicolumn{5}{|l|}{ Primary treatment } \\
\hline SBRT & 22 & 10 & 12 & \multirow[t]{2}{*}{0.005} \\
\hline Surgery & 51 & 40 & 11 & \\
\hline \multicolumn{5}{|l|}{ ECOG (0-4) } \\
\hline 0 & 55 & 39 & 16 & \multirow[t]{3}{*}{0.336} \\
\hline 1 & 16 & 9 & 7 & \\
\hline 2 & 2 & 2 & 0 & \\
\hline \multicolumn{5}{|l|}{$\mathrm{FEV}_{1}$ (percentage } \\
\hline $\begin{array}{l}\text { DLCO (percentage } \\
\text { of predicted) }\end{array}$ & $64( \pm 20)$ & $68( \pm 20)$ & $57( \pm 18)$ & $\begin{array}{l}0.010 \\
0.038\end{array}$ \\
\hline \multicolumn{5}{|l|}{ Morphology } \\
\hline SCC & 16 & 13 & 3 & \multirow[t]{3}{*}{0.437} \\
\hline $\mathrm{AC}$ & 33 & 22 & 11 & \\
\hline Unknown & 24 & 15 & 9 & \\
\hline $\begin{array}{l}\text { No. of CT scans; } \\
\text { median (range) }\end{array}$ & n.a. & n.a. & $1(4)$ & n.a. \\
\hline $\begin{array}{l}\text { No. of chest-RG; } \\
\text { median (range) }\end{array}$ & $4(0-14)$ & $5(13)$ & $3(13)$ & n.a. \\
\hline \multicolumn{5}{|l|}{ Kind of recurrence } \\
\hline DR & 52 & 37 & 15 & \multirow[t]{2}{*}{0.441} \\
\hline LRR & 21 & 13 & 8 & \\
\hline \multicolumn{5}{|l|}{ Prove of recurrence } \\
\hline Radiologic imaging & 31 & 23 & 8 & \multirow[t]{3}{*}{0.604} \\
\hline Pathology & 40 & 26 & 14 & \\
\hline Other & 2 & 1 & 1 & \\
\hline
\end{tabular}

AC, Adenocarcinoma; chest-RG, chest radiography; c-TNM, clinical TNM; DLCO, diffusing capacity of the lung for carbon monoxide; DR, distance recurrence; ECOG, eastern cooperative oncology group performance status; $\mathrm{FEV}_{1}$, forced expiratory volume in 1 second; LRR, locoregional recurrence; n.a., not applicable; PY, pack years; SBRT, stereotactic body radiotherapy; SCC, squamous cell carcinoma.

The 1-year survival was $80 \%$ in the CR group versus $91 \%$ in the CT group $(\mathrm{HR}=5.544,95 \% \quad \mathrm{CI}=0.530-58.031$, $p=0.153$ ) and the 3-year survival was $30 \%$ versus $39 \%$ $(\mathrm{HR}=1.540,95 \% \mathrm{CI}=0.752-3.154, p=0.238)$.

Progression-free survival. The same candidate factors as for the OS were tracked (Table III). On multivariate analysis, ECOG

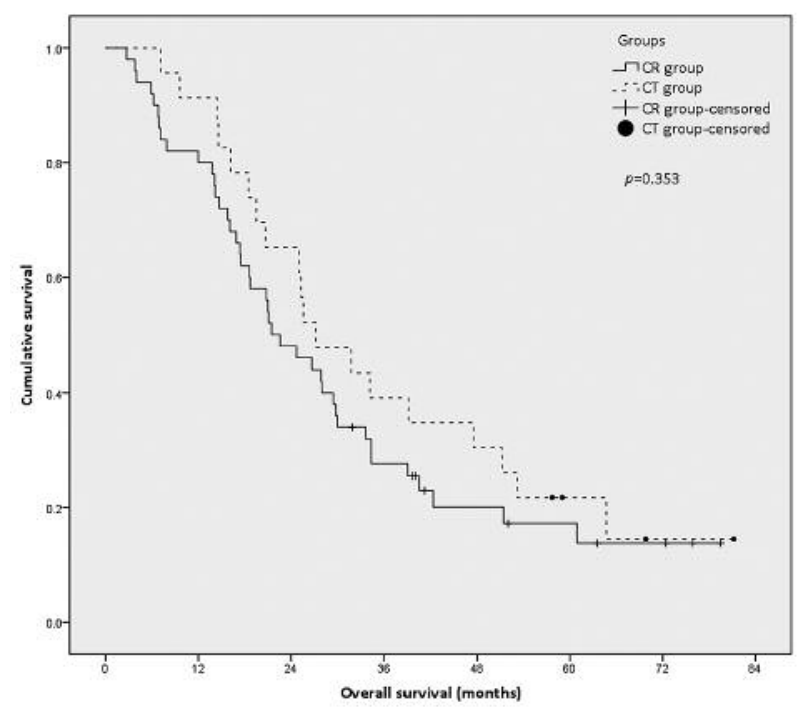

Figure 1. Kaplan-Meier of the overall survival. CR, Chest radiography; $C T$, computed tomography.

has a statistically significant relationship with PFS; patients with an ECOG $0(\mathrm{HR}=0.063,95 \% \mathrm{CI}=0.010-0.414, p=0.004)$ and ECOG $1(\mathrm{HR}=0.086,95 \% \mathrm{CI}=0.015-0.489, p=0.006)$ are at lower risk for dying than patients with ECOG 2.

The median PFS in the CR group was 14.7 months (IQR=8.3-26.4) compared to 13.5 months $(\mathrm{IQR}=8.8-28.0)$ in the CT group $(p=0.786)$. Receiving chest radiographs only did not give an inferior PFS $(\mathrm{HR}=1.156,95 \% \mathrm{CI}=0.645$ 2.069, $p=0.627$ ) and did not influence survival, $p=0861$ (Figure 2).

\section{Discussion}

This retrospective study about follow-up in both surgical and SBRT patients with curatively treated stage I and II NSCLC showed that there is no difference in OS and PFS between the groups receiving follow-up only by chest radiographs compared to a surveillance with CT scans. This might lead to the suggestion that a CT scan is not necessarily to be done during follow-up.

It is remarkable that, in our study, most patients who received a CT scan anywhere in their follow-up, received it in the first year of follow-up (67\%). This was comparable to the trend seen by Sharma et al. (15); they noticed a decrease from $41.2 \%$ to $27.3 \%$ in the number of CT scans made during five years of follow-up. The outcomes in this study were comparable with the observational data from Sharma et al. (15). While using the same way of counting radiological examinations, they found a 15-month survival of $84 \%$ for the whole cohort; the 12-month survival in our whole cohort was $84 \%$. 
Table II. Univariate and multivariate analysis for OS.

\begin{tabular}{|c|c|c|c|c|}
\hline & \multicolumn{2}{|c|}{$\begin{array}{l}\text { Overall survival } \\
\text { Univariate analysis }\end{array}$} & & \\
\hline & HR $(95 \% \mathrm{CI})$ & $p$-Value & & \\
\hline \multirow{4}{*}{$\begin{array}{l}\text { Gender (male } v s . \text { female) } \\
\text { Age (continuous) }\end{array}$} & $0.869(0.522-1.446)$ & 0.588 & & \\
\hline & $0.988(0.964-1.012)$ & 0.323 & \multirow{2}{*}{\multicolumn{2}{|c|}{ Multivariate analysis }} \\
\hline & & & & \\
\hline & & & HR $(95 \% \mathrm{CI})$ & $p$-Value \\
\hline $\mathrm{FEV}_{1}$ (continuous) & $0.990(0.979-1.002)$ & 0.095 & $0.995(0.975-1.016)$ & 0.650 \\
\hline DLCO (continuous) & $0.989(0.976-1.003)$ & 0.119 & $0.991(0.970-1.011)$ & 0.375 \\
\hline ECOG 2 (ref.) & & $<0.000$ & & 0.024 \\
\hline ECOG 0 & $0.035(0.006-0.200)$ & $<0.000$ & $0.060(0.008-0.453)$ & 0.006 \\
\hline ECOG 1 & $0.061(0.010-0.361)$ & 0.002 & $0.091(0.014-0.584)$ & 0.011 \\
\hline Morphology; other (ref.) & & 0.059 & & 0.109 \\
\hline Morphology; squamous cell & $0.430(0.208-0.889)$ & 0.023 & $0.345(0.124-0.957)$ & 0.041 \\
\hline Morphology; adenocarcinoma & $0.629(0.358-1.107)$ & 0.108 & $0.597(0.236-1.508)$ & 0.275 \\
\hline Primary treatment; SBRT vs. surgery & $1.524(0.896-2.594)$ & 0.120 & $0.515(0.137-1.934)$ & 0.326 \\
\hline
\end{tabular}

CI, Confidence interval; DLCO, diffusing capacity of the lung for carbon monoxide; ECOG, eastern cooperative oncology group performance status; $\mathrm{FEV}_{1}$, forced expiratory volume in 1 second; HR, hazard ratio; SBRT, stereotactic body radiotherapy.

There were no well-comparable studies about the imaging modality in follow-up after curative-intended treated stage I and II NSCLC. Westeel et al. (16) started a randomized multicenter study to compare two surveillance schemes: one with a CT and bronchoscopy the other with physical examination and a chest radiography. The results are pending.

One study showed that the way of follow-up in the initial phase after surgery (4-8 months) resulted in a 5-year survival of $58 \%$ for a chest radiography versus $61 \%$ for a CT scan (17). An initial CT scan did not give a superior 5-year survival compared to no initial imaging $(p=0.110)$. Both a chest radiography $(\mathrm{HR}=1.08,95 \% \mathrm{CI}=1.01-1.16, p=0.032)$ and CT scan $(\mathrm{HR}=1.04,95 \% \mathrm{CI}=0.96-1.14, p=0.344) \mathrm{did}$ not give a reduced risk of death. Unfortunately, there is no statistical analysis about the added value of a CT scan above chest radiography. A second outcome, on subgroup analysis, showed that patients with stage I NSCLC might have benefits from initial surveillance with $\mathrm{CT}$ scan in contrast to patients with stage II (17). Comparison with this study is not easy because our study focused on the whole period of follow-up until progression of disease instead of the initial surveillance and included both surgical and SBRT patients instead of only surgical patients. Spratt et al. (18) undertook a research to provide an appropriate schedule for follow-up in patients treated with SBRT; however, no clear single answer could be given.

One study compared prospectively two schedules of follow-up: physical examination and chest radiography

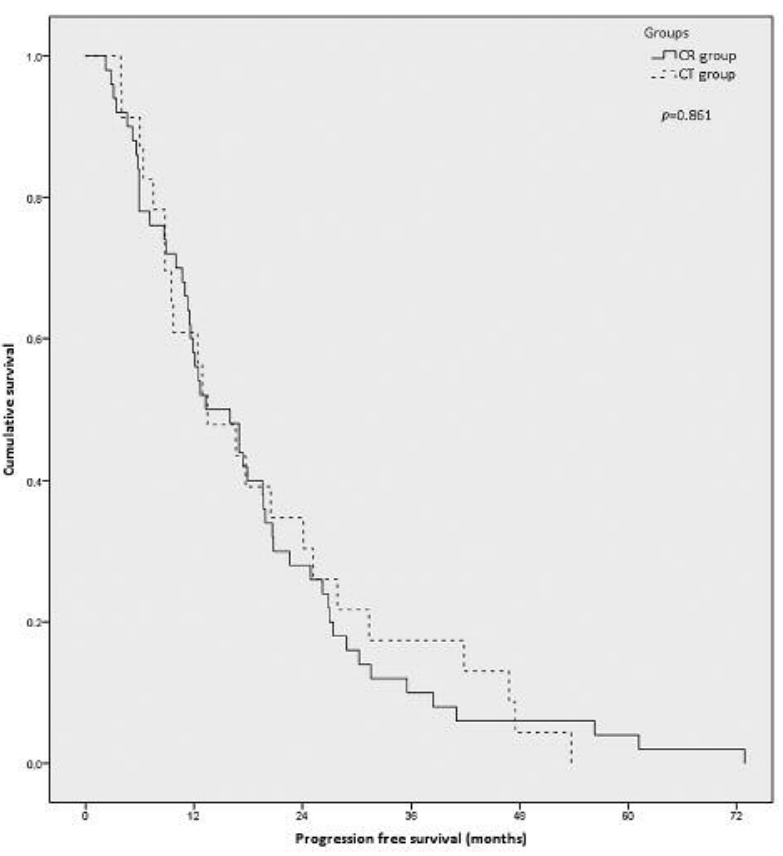

Figure 2. Kaplan-Meier of the progression free survival. CR, Chest radiography; CT, computed tomography.

versus CT scan and fiberoptic bronchoscopy (19). The median PFS was 19 months (range=1-198). The 3-year survival from recurrence till death or last date of follow-up was statistically longer in patients with asymptomatic tumor 
Table III. Univariate and multivariate analysis for PFS.

\begin{tabular}{|c|c|c|c|c|}
\hline & \multicolumn{2}{|c|}{$\begin{array}{l}\text { Progression-free survival } \\
\text { Univariate analysis }\end{array}$} & & \\
\hline & $\mathrm{HR}(95 \% \mathrm{CI})$ & $p$-Value & & \\
\hline \multirow{4}{*}{$\begin{array}{l}\text { Gender (male vs. female) } \\
\text { Age (continuous) }\end{array}$} & $1.028(0.643-1.642)$ & 0.909 & \multirow{3}{*}{\multicolumn{2}{|c|}{ Multivariate analysis }} \\
\hline & $0.982(0.959-1.006)$ & 0.151 & & \\
\hline & & & & \\
\hline & & & $\mathrm{HR}(95 \% \mathrm{CI})$ & $p$-Value \\
\hline $\mathrm{FEV}_{1}$ (continuous) & $0.995(0.985-1.005)$ & 0.331 & $0.992(0.974-1.010)$ & 0.367 \\
\hline DLCO (continuous) & $0.996(0.984-1.008)$ & 0.537 & $0.999(0.982-1.016)$ & 0.901 \\
\hline ECOG 2 (ref.) & & 0.004 & & 0.014 \\
\hline ECOG 0 & $0.072(0.015-0.347)$ & 0.001 & $0.063(0.010-0.414)$ & 0.004 \\
\hline ECOG 1 & $0.086(0.017-0.435)$ & 0.003 & $0.086(0.015-0.489)$ & 0.006 \\
\hline Morphology; other (ref.) & & 0.125 & & 0.085 \\
\hline Morphology; squamous cell & $0.520(0.274-0.990)$ & 0.047 & $0.397(0.157-1.005)$ & 0.051 \\
\hline Morphology; adenocarcinoma & $0.856(0.502-1.461)$ & 0.569 & $0.714(0.292-1.748)$ & 0.461 \\
\hline Primary treatment; SBRT vs. surgery & $1.186(0.713-1.971)$ & 0.512 & $0.414(0.123-1.392)$ & 0.154 \\
\hline
\end{tabular}

CI, Confidence interval; DLCO, diffusing capacity of the lung for carbon monoxide; ECOG, eastern cooperative oncology group performance status; $\mathrm{FEV}_{1}$, forced expiratory volume in 1 second; HR, hazard ratio; SBRT, stereotactic body radiotherapy.

recurrence $(31 \%)$ versus $10 \%$ in symptomatic patients $(\mathrm{HR}=0.46, \mathrm{CI}=0.29-073, \mathrm{p}<0.001)$. Unfortunately, the 3 -year survival was unequal to compare, due to a different definition. Moreover, this study turned out to have a biased patient population (59\% underwent pneumonectomy), which leads to doubtful clinical interpretation. Kent et al. (20) and Korst et al. (11) supported that CT scan might not give superior clinical outcomes; their studies suggested that routinely scanning with $\mathrm{CT}$ scan was not cost-effective and, moreover, chest CT scan had a low positive predicting value for recurrences of $53 \%(11,20,21)$.

A systematic review and meta-analysis about the survival benefits from intensive follow-up of patients with both small-cell lung cancer and NSCLC (all stages) showed that there is a paucity of evidence for different imaging modalities (21). They identified six small retrospective studies that showed a trend towards improvement in OS with a more intensive schedule with $\mathrm{CT}$ scan $(\mathrm{HR}=0.83$; $\mathrm{CI}=0.66$ $1.05 ; p=0.13$ ).

This study has some limitations. First, it is a retrospective study. Second, it is a single-center study. Third, it includes a small number of patients. Due to this small number of patients, we were unable to give appropriate implications for the best modality and frequency of follow-up and unable to analyze the subgroup of patients receiving only CT scans. The study, however, showed no difference in both imaging modality groups.
In the current study, PET scans were not performed on regular basis in accordance to the guidelines, though it is remarkable that there is increasing attention to PET for regular follow-up after primarily curative treatment in early-stage NSCLC $(22,23)$ and a growth of usage of PET scans (15).

In accordance to the Dutch guideline (24) and the ACCP, routinely chest radiographs provide good information, while CT is not necessarily to be done and could lead to falsepositive scans and time bias (11). However, there might be other reasons to recommend a CT scan, like the patients' emotional distress, the patient-doctor relationship, medicolegal liability and feedback for the surgeon to improve his techniques $(15,21,25)$.

In conclusion, our study showed that, in patients diagnosed with stage I and II NSCLC and treated with SBRT or surgery, a follow-up with only chest radiographs did not give clinical outcomes that are inferior compared to patients who received a CT scan anywhere in their follow-up. However, a clear answer to the best modality and frequency for follow-up after curative-intended treatment for NSCLC is not provided. Prospective studies will need to be done to provide this information.

\section{Acknowledgements}

The Authors are very grateful to the collaborators of the library of the Sint Antonius Hospital, Nieuwegein. 


\section{References}

1 Ferlay J, Soerjomataram I, Dikshit R, Eser S, Mathers C, Rebelo M, Parkin DM, Forman D and Bray F: Cancer incidence and mortality worldwide: sources, methods and major patterns in GLOBOCAN 2012. Int J Cancer 136: E359-86, 2015.

2 Howlader N, Noone AM, Krapcho M, Miller D, Bishop K, Altekruse SF, Kosary CL, Yu M, Ruhl J, Tatalovich Z, Mariotto A, Lewis DR, Chen HS, Feuer EJ, Cronin KA (eds): SEER Cancer Statistics Review, 1975-2013, National Cancer Institute. Bethesda, MD: 2016-7-1.

3 Solda F, Lodge M, Ashley S, Whitington A, Goldstraw P and Brada M: Stereotactic radiotherapy (SABR) for the treatment of primary non-small cell lung cancer; systematic review and comparison with a surgical cohort. Radiother Oncol 109: 1-7, 2013.

4 Kastelijn EA, El Sharouni SY, Hofman FN, Van Putte BP, Monninkhof EM, Van Vulpen M and Schramel FM: Clinical outcomes in early-stage NSCLC Treated with stereotactic body radiotherapy versus surgical resection. Anticancer Res 35: 5607$5614,2015$.

5 Louie AV, van Werkhoven E, Chen H, Smit EF, Paul MA, Widder J, Groen HJ, van den Borne BE, De Jaeger K, Slotman BJ and Senan S: Patient reported outcomes following stereotactic ablative radiotherapy or surgery for stage IA nonsmall-cell lung cancer: Results from the ROSEL multicenter randomized trial. Radiother Oncol 117: 44-48, 2015.

6 Hubbard MO, Fu P, Margevicius S, Dowlati A and Linden PA: Five-year survival does not equal cure in non-small cell lung cancer: A Surveillance, Epidemiology, and End Results-based analysis of variables affecting 10-to 18-year survival. J Thorac Cardiovasc Surg 143: 1307-1313, 2012.

7 National Lung Screening Trial Research Team, Aberle DR, Adams AM, Berg CD, Black WC, Clapp JD, Fagerstrom RM, Gareen IF, Gatsonis C, Marcus PM and Sicks JD: Reduced lungcancer mortality with low-dose computed tomographic screening. N Engl J Med 365: 395-409, 2011.

8 Alberts WM: Follow-up and surveillance of the patient with lung cancer: What do you do after surgery?. Respirology 12: 16-21, 2007.

9 Sugimura H, Nichols FC, Yang P, Allen MS, Cassivi SD, Deschamps C, Williams BA and Pairolero PC: Survival after recurrent nonsmall-cell lung cancer after complete pulmonary resection. Ann Thorac Surg 83: 409-418, 2007.

10 Boone JM, Hendee WR, McNitt-Gray MF and Seltzer SE: Radiation exposure from CT scans: how to close our knowledge gaps, monitor and safeguard exposure - proceedings and recommendations of the Radiation Dose Summit, sponsored by NIBIB, February 24-25, 2011. Radiology 265: 544-554, 2012.

11 Korst RJ, Kansler AL, Port JL, Lee PC and Altorki NK: Accuracy of surveillance computed tomography in detecting recurrent or new primary lung cancer in patients with completely resected lung cancer. Ann Thorac Surg 82: 1009-1015, 2006.

12 Crino L, Weder W, van Meerbeeck J, Felip E and ESMO Guidelines Working Group: Early stage and locally advanced (non-metastatic) non-small-cell lung cancer: ESMO Clinical Practice Guidelines for diagnosis, treatment and follow-up. Ann Oncol 21(Suppl 5): v103-15, 2010.

13 Benson A and Chan E: NCCN Guidelines Version 3.2013. Available online:, on February 20, 2013.
14 Rubins J, Unger M, Colice GL and American College of Chest Physicians: Follow-up and surveillance of the lung cancer patient following curative intent therapy: ACCP evidence-based clinical practice guideline (2nd edition). Chest 132: 355S-367S, 2007.

15 Sharma G, Nishi SP, Lin Y, Kuo Y, Goodwin JS and Riall TS: Pattern of imaging following lung cancer resection: 1992-2005. Ann Thorac Surg, 2016.

16 Westeel V, Lebitasy MP, Mercier M, Girard P, Barlesi F, Blanchon F, Tredaniel J, Bonnette P, Woronoff-Lemsi MC, Breton JL, Azarian R, Falcoz PE, Friard S, Geriniere L, Laporte S, Lemarie E, Quoix E, Zalcman G, Guigay J, Morin F, Milleron B, Depierre A and Intergroupe Francophone de Cancerologie Thoracique (IFCT): IFCT-0302 trial: randomised study comparing two follow-up schedules in completely resected nonsmall cell lung cancer. Rev Mal Respir 24: 645-652, 2007.

17 Backhus LM, Farjah F, Liang CK, He H, Varghese TK Jr., Au DH, Flum DR and Zeliadt SB: Imaging surveillance and survival for surgically resected non-small-cell lung cancer. J Surg Res 200: 171-176, 2016.

18 Spratt DE, Wu AJ, Adeseye V, Din SU, Shaikh F, Woo KM, Zhang Z, Foster A, Rosenzweig KE, Gewanter R, Huang J and Rimner A: Recurrence patterns and second primary lung cancers after stereotactic body radiation therapy for early-stage nonsmall-cell lung cancer: Implications for Surveillance. Clin Lung Cancer 17: 177-183.e2, 2016.

19 Westeel V, Choma D, Clément F, Woronoff-Lemsi M, Pugin J, Dubiez A and Depierre A: Relevance of an intensive postoperative follow-up after surgery for non-small cell lung cancer. Ann Thorac Surg 70: 1185-1190, 2000.

20 Kent MS, Korn P, Port JL, Lee PC, Altorki NK and Korst RJ: Cost effectiveness of chest computed tomography after lung cancer resection: a decision analysis model. Ann Thorac Surg 80: 1215-1223, 2005.

21 Calman L, Beaver K, Hind D, Lorigan P, Roberts C and LloydJones M: Survival benefits from follow-up of patients with lung cancer: a systematic review and meta-analysis. J Thorac Oncol 6: 1993-2004, 2011.

22 Dane B, Grechushkin V, Plank A, Moore W and Bilfinger T: PET/CT vs. non-contrast CT alone for surveillance 1-year post lobectomy for stage I non-small-cell lung cancer. Am J Nucl Med Mol Imaging 3: 408-416, 2013.

23 Ebright MI, Russo GA, Gupta A, Subramaniam RM, Fernando HC and Kachnic LA: Positron emission tomography combined with diagnostic chest computed tomography enhances detection of regional recurrence after stereotactic body radiation therapy for early stage non-small cell lung cancer. J Thorac Cardiovasc Surg 145: 709-715, 2013.

24 Landelijke Werkgroep Longtumoren: [Guideline non-small cell lung cancer, version 2.3], 2015.

25 Chiu C, Chern M, Wu M, Hsu W, Wu Y, Huang M and Chang S: Usefulness of low-dose spiral CT of the chest in regular follow-up of postoperative non-small cell lung cancer patients: preliminary report. J Thorac Cardiovasc Surg 125: 1300-1305, 2003.

Received August 12, 2016

Revised August 30, 2016

Accepted August 31, 2016 